\title{
The intracellular domain of $\beta$-dystroglycan mediates the nucleolar stress response by suppressing UBF transcriptional activity
}

\author{
Paulina Margarita Azuara-Medina', Ariana María Sandoval-Duarte', Sara L. Morales-Lázaro², \\ Ricardo Modragón-González', Griselda Vélez-Aguilera', Juan de Dios Gómez-López', \\ Guadalupe Elizabeth Jiménez-Gutiérrez', Reynaldo Tiburcio-Félix', Ivette Martínez-Vieyra ${ }^{3}$, Rocío Suárez-Sánchez ${ }^{4}$, \\ Gernot Längst ${ }^{5}$, Jonathan Javier Magaña ${ }^{4}$, Steve J. Winder ${ }^{6}$, Arturo Ortega $\mathbb{1}^{7}$, Rita de Cassia Ramos Perlingeiro ${ }^{8}$, \\ Laura A. Jacobs ${ }^{6}$ and Bulmaro Cisneros (D) ${ }^{1}$
}

\begin{abstract}
$\beta$-dystroglycan ( $\beta$-DG) is a key component of multiprotein complexes in the plasma membrane and nuclear envelope. In addition, $\beta-D G$ undergoes two successive proteolytic cleavages that result in the liberation of its intracellular domain (ICD) into the cytosol and nucleus. However, stimuli-inducing ICD cleavage and the physiological relevance of this proteolytic fragment are largely unknown. In this study we show for the first time that $\beta$-DG ICD is targeted to the nucleolus where it interacts with the nuclear proteins B23 and UBF (central factor of Pol I-mediated rRNA gene transcription) and binds to rDNA promoter regions. Interestingly DG silencing results in reduced B23 and UBF levels and aberrant nucleolar morphology. Furthermore, $\beta-D G$ ICD cleavage is induced by different nucleolar stressors, including oxidative stress, acidosis, and UV irradiation, which implies its participation in the response to nucleolar stress. Consistent with this idea, overexpression of $\beta$-DG elicited mislocalization and decreased levels of UBF and suppression of rRNA expression, which in turn provoked altered ribosome profiling and decreased cell growth. Collectively our data reveal that $\beta-D G I C D$ acts as negative regulator of rDNA transcription by impeding the transcriptional activity of UBF, as a part of the protective mechanism activated in response to nucleolar stress.
\end{abstract}

\section{Introduction}

Regulated proteolysis of cell surface receptors that liberates biologically active proteins/peptides from the plasma membrane (PM) to the cytosol is a critical step in a variety of different signaling pathways that respond to external

\footnotetext{
Correspondence: Bulmaro Cisneros (bcisnero@cinvestav.mx)

${ }^{1}$ Departamento de Genética y Biología Molecular, Centro de Investigación y de Estudios Avanzados Del Instituto Politécnico Nacional, 07360 Ciudad de México, Mexico

${ }^{2}$ Departamento de Neurociencia Cognitiva, Instituto de Fisiología Celular, Universidad Nacional Autónoma de México, 04510 Ciudad de México, Mexico Full list of author information is available at the end of the article.

Edited by S. Lavandero
}

stimuli. $\gamma$-Secretase is an intramembranous cleaving protease complex consisting of at least four proteins: presenilin-1, nicastrin, anterior pharynx-defective phenotype 1 , and presenilin enhancer $2^{1} . \gamma$-Secretase is known to be required for the activation of many transmembrane proteins, including the amyloid precursor protein, cadherins, Notch $^{2}$, and recently, dystroglycan ${ }^{3,4}$. Dystroglycan, a key component of the dystrophin-associated protein complex (DAPC), is transcribed from the DAG1 gene and translated as a single propeptide, which is proteolytically processed to generate the extracellular subunit $\alpha$-dystroglycan $(\alpha-D G)$ and the transmembrane subunit $\beta$-dystroglycan $(\beta-D G)^{5}$. $\alpha$-DG binds to different extracellular matrix proteins

\section{(c) The Author(s) 2019}

(c) (i) Open Access This article is licensed under a Creative Commons Attribution 4.0 International License, which permits use, sharing, adaptation, distribution and reproduction c. in any medium or format, as long as you give appropriate credit to the original author(s) and the source, provide a link to the Creative Commons license, and indicate if changes were made. The images or other third party material in this article are included in the article's Creative Commons license, unless indicated otherwise in a credit line to the material. If material is not included in the article's Creative Commons license and your intended use is not permitted by statutory regulation or exceeds the permitted use, you will need to obtain permission directly from the copyright holder. To view a copy of this license, visit http://creativecommons.org/licenses/by/4.0/. 
including laminin, agrin, or perlecan ${ }^{6}$, while $\beta$-DG connects actin through various cytolinker proteins including dystrophin or utrophin. Thereby, dystroglycan serves as a link between the extracellular matrix and the actin-based cytoskeleton, acting also as an adhesion and signaling receptor ${ }^{5,7}$.

Besides its structural role in the maintenance of membrane integrity, dystroglycan localization is not static but dynamic. Phosphorylation of $\beta$-DG at $Y^{890}$ triggers its retrograde trafficking from $\mathrm{PM}$ to the nucleus, via the membranous endosome-endoplasmic reticulum (ER) network, with ezrin activation enhancing the intracellular trafficking and translocon Sec61 facilitating the exit of $\beta$ DG from the ER membrane to be accessible for importindependent nuclear import through the nuclear pore ${ }^{8-10}$. In the nucleus, $\beta$-DG is assembled with nuclear envelope (NE) components, including emerin, and lamins $\mathrm{A} / \mathrm{C}$ and $\mathrm{B} 1$, to preserve the nuclear structure/function ${ }^{11,12}$ and where it can also indirectly regulate gene expression ${ }^{13}$. This functional diversity of $\beta$-DG, acting as a platform for both PM- and NE-associated processes, is further expanded by proteolytic cleavage of the protein. $\beta$-DG is subjected to proteolytic cleavage by MMP-2 and MMP-9 to liberate its extracellular domain ${ }^{14,15}$, while the remaining fragment, containing the transmembrane stub and the cytoplasmic portion is thought to be subsequently processed by $\gamma$-secretase to deliver an intracellular domain (ICD; $12 \mathrm{kDa}$ in mass but runs aberrantly on SDSPAGE at $\sim 26 \mathrm{kDa}$ ) into the cytosol ${ }^{3,4}$. Recent evidence showed that $\beta$-DG ICD is targeted to the nucleus in prostate cancer cells ${ }^{3,13,16}$ nonetheless the biological significance of such localization is largely unknown. The nucleus is organized into distinct functional compartments containing specific macromolecules that govern nuclear processes; ${ }^{16}$ for instance, the nucleolus is a prominent non-membranous nuclear organelle primarily involved in ribosome biogenesis and cellular homeostasis $^{17}$. Thus, identification of the destination of $\beta$-DG ICD within the nucleus could facilitate further elucidation of its function.

In this study we demonstrate for the first time that $\beta$-DG ICD is target to the nucleolus where it plays a negative role in the regulation of ribosomal RNA (rRNA) transcription. We provide evidence that full-length $\beta$-DG is proteolytically processed into $\beta$-DG ICD in response to nucleolar stress, via the Notch signaling pathway. Remarkably, $\beta$-DG ICD binds to the rDNA promoter to suppress rRNA synthesis by impairing the expression, localization, and ultimately activity of the RNA polymerase I (Pol I) transcription factor UBF (upstream binding factor), which further results in the downregulation of rRNA expression and cell proliferation. Thus, $\beta$-DG ICD appears to be a key contributor to the nucleolar stress response.

\section{Results}

The $\gamma$-secretase-generated intracellular domain of $\beta$-DG is targeted to the nucleolus

We previously observed localization of $\beta$-DG to the nucleoli in $\mathrm{C} 2 \mathrm{C} 12$ myoblasts ${ }^{11}$; but no role for $\beta$-DG has been described in this nuclear organelle. As a first step, we analyzed whether $\beta$-DG colocalizes with proteins that define functionally distinct compartments of the nucleolus. Cells were double-stained for $\beta$-DG (C20 antibody) along with UBF, fibrillarin (markers of the fibrillar center, FC), or B23 (marker of the granular component, GC) and further analyzed by confocal microscopy. The nucleolar immunostaining of $\beta$-DG colocalized at certain extent with all three nucleolar proteins analyzed, as confirmed by the line intensity scan analysis and Manders' overlapping coefficients (Fig. 1a). The specificity of $\mathrm{C} 20$ antibody was demonstrated using both DG knockout $\mathrm{C} 2 \mathrm{C} 12$ cells and primary fibroblasts from a subject with Walker-Warburg syndrome that do not express DAG1 gene all ${ }^{18}$. Nucleoli were strongly staining by $\mathrm{C} 20$ in $\mathrm{C} 2 \mathrm{C} 12$ wild-type cells, while a faint nuclear staining that was excluded from nucleoli was observed in DG knockout $\mathrm{C} 2 \mathrm{C} 12$ cells (Supplementary Figure 1A, left panel). Furthermore, the immunoreactive band corresponding to $\beta$-DG $(\sim 43 \mathrm{kDa})$, which was observed in primary fibroblast lysates from a healthy subject, was absent in Walker-Warburg syndrome primary fibroblast lysates (Supplementary Figure $1 \mathrm{~A}$, right panel). Finally, pre-incubation with a blocking peptide virtually eliminated C20 immunostaining in wild-type cells (Supplementary Figure 1B). In addition, nucleolar localization of $\beta$-DG was confirmed using another anti- $\beta$-DG antibody (G5; Supplementary Figure $1 \mathrm{C})$. The nucleolus is a highly dynamic organelle that responds to a variety of cellular stresses with morphological changes ${ }^{19}$ and redistribution of proteins implicated in ribosome biogenesis form perinuclear caps upon inhibition of rDNA transcription ${ }^{20}$. C2C12 cells were therefore treated with actinomycin $\mathrm{D}(0.08 \mu \mathrm{g} / \mathrm{ml})$ or DRB $(0.3 \mu \mathrm{M})$ to cause nucleolar stress, and the effect of treatments on $\beta$-DG distribution was evaluated by confocal microscopy. The formation of nucleolar caps and nucleolar segregation/nucleolar necklaces was found after treatment with Act D and DRB, respectively, as shown by immunostaining for UBF and B23 (Fig. 1b). Treatment with the vehicle alone dimethyl sulfoxide (DMSO) produced no change in the immunostaining pattern of nucleolar proteins. Interestingly, nucleolar labeling of $\beta$ DG also underwent redistribution in response to Act $D$ and DRB but remained in colocalization partially with UBF and barely with B23, as shown by Manders' overlapping coefficient analysis (Fig. 1b), suggesting that $\beta$-DG might be involved in nucleolar organization/plasticity. Next, we investigated whether the nucleolar localization of $\beta$-DG is dependent on nucleic acid integrity. $\mathrm{C} 2 \mathrm{C} 12$ 


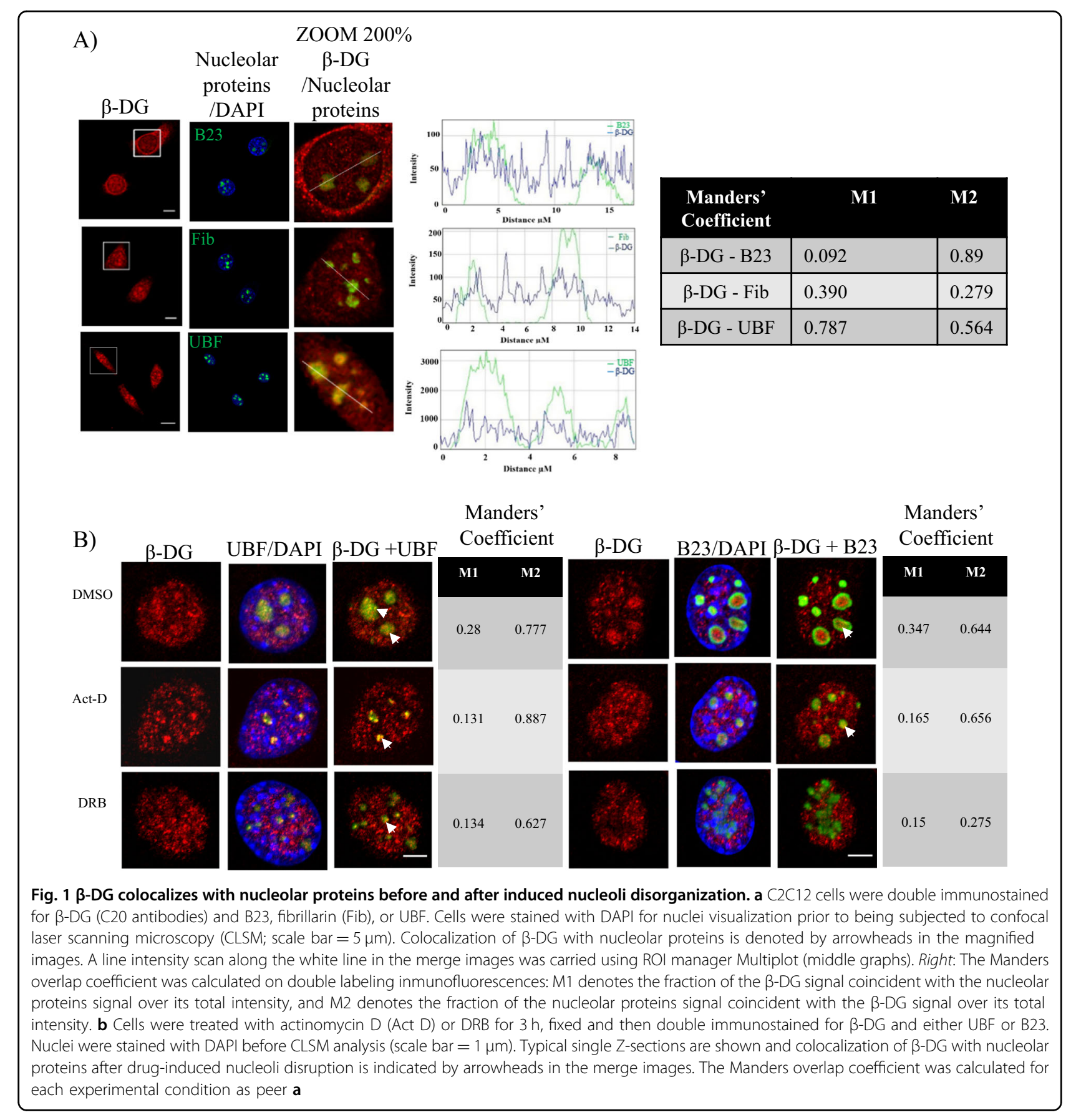

myoblasts were immunolabeled for $\beta$-DG before and after nuclease treatment, and stained with DAPI to monitor DNA degradation, or immunolabeled for hnRNP C1/C2 antibody (RNA-binding protein) to monitor RNA removal. DNase digestion completely removed DAPIlabeled DNA, while treatment with RNase caused hnRNP $\mathrm{C} 1 / \mathrm{C} 2$ redistribution from the nucleoplasm to the nuclear periphery and cytoplasm, thus confirming the effectiveness of nucleases treatment. DNase treatment completely abrogated the nucleolar distribution of $\beta-D G$, while treatment with RNase apparently increased the intensity of $\beta$-DG nucleolar immunostaining, compared with untreated cells (Supplementary Figure 2A and B). These results suggest that the nucleolar localization of $\beta-D G$ is dependent on DNA.

To demonstrate conclusively that $\beta$-DG resides in the nucleolus, $\mathrm{C} 2 \mathrm{C} 12$ were fractionated into total, cytoplasmic, nuclear, and nucleolar fractions to be further analyzed by SDS-PAGE/WB. A prominent $\sim 30 \mathrm{kDa} \beta-\mathrm{DG}$ band was found enriched, together with fibrillarin, in the 

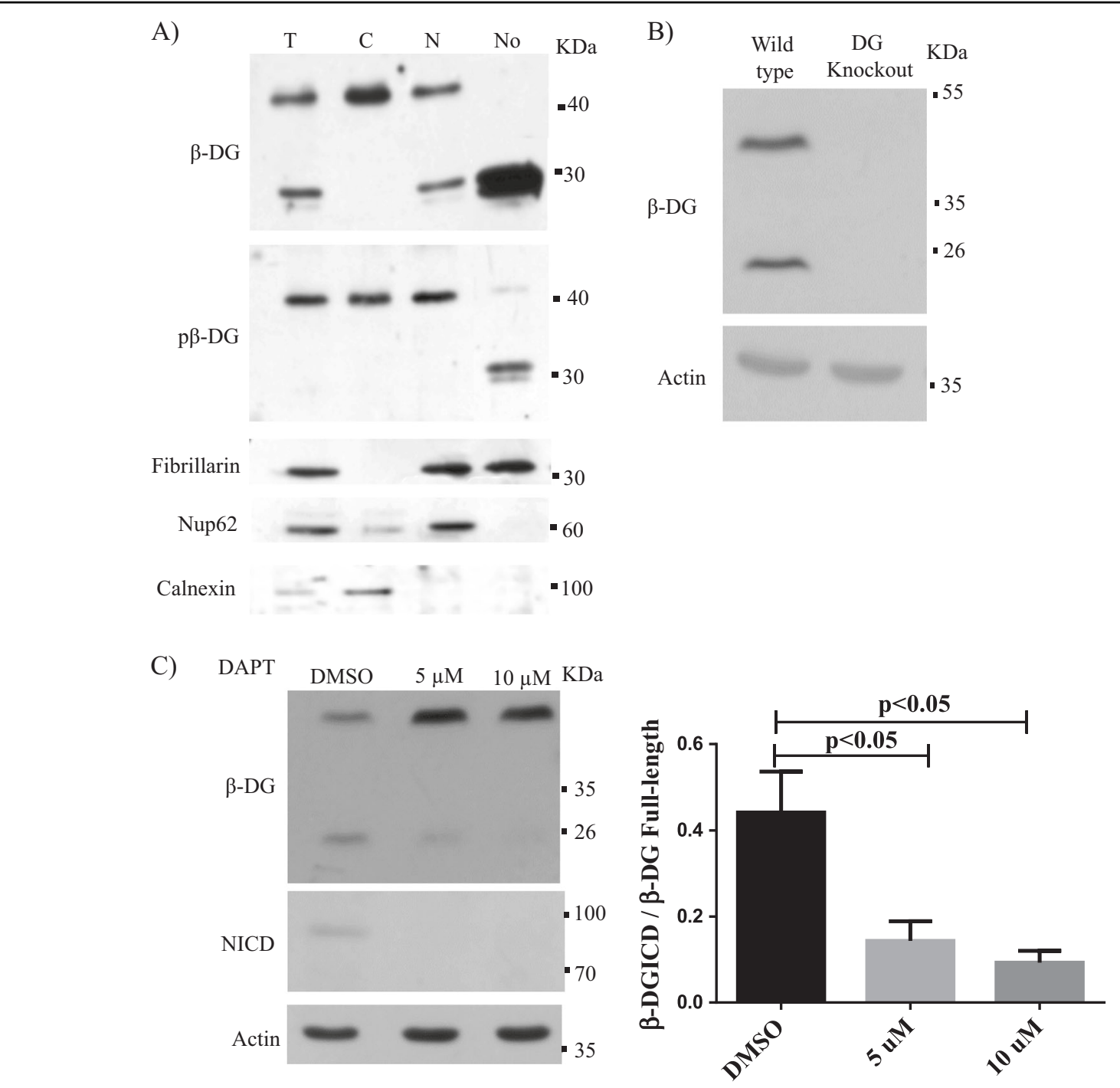

Fig. $2 \beta$-DG ICD resides in the nucleolus. a Cells were partitioned to obtain total (T), cytoplasmic (C), nuclear (N), and nucleolar (No) fractions, prior to SDS-PAGE/WB analysis, using specific antibodies for $\beta$-DG (Mandag) or its phosphorylated counterpart (p $\beta$-DG). Fibrillarin (nucleolar protein), Nup62 (nuclear membrane protein), and calnexin (reticulum endoplasmic protein) were used as cellular fraction markers. b Lysates from wild-type and DG knockout C2C12 cells were analyzed by SDS-PAGE/WB using antibodies for $\beta$-DG (Mandag) and actin (loading control), to demonstrate $\beta$-DG antibody specificity. $\mathbf{c}$ Lysates from $\mathrm{C} 2 \mathrm{C} 12$ cells treated for $24 \mathrm{~h}$ with the indicated concentrations DAPT ( $\gamma$-secretase inhibitor) or the vehicle alone (DMSO) were analyzed by SDS-PAGE/WB, using antibodies for $\beta-D G$, Notch intracellular domain (NICD; positive control for DAPT action), and actin (loading control). Representative gel from three independent experiments is shown. Right. Data correspond to the mean \pm SEM from three independent experiment, with $p$ values indicating significant differences (unpaired $t$-test)

nucleolar fraction, as revealed using three different anti- $\beta$ DG antibodies: MANDAG (mouse mab that recognizes total $\beta$-DG levels), pTyr890 (rabbit pAb that specifically recognizes $\beta$-DG phosphorylated at $\mathrm{Tyr}^{890}$ ) (Fig. 2a), and C20 (rabbit antibody that recognizes the total $\beta$-DG pool Supplementary Figure 1D). Nup62 (nuclear pore protein) and calnexin (endoplasmic reticulum protein) were recovered in the nuclear and cytoplasmic fractions, respectively, and the two proteins were absent from the nucleolar fraction demonstrating that no crosscontamination occurred during cellular fractionation.
Control experiments using both DG knockout $\mathrm{C} 2 \mathrm{C} 12$ cells and Walker-Warburg syndrome primary fibroblasts yield no immunoreactive bands after incubation with MANDAG antibody (Fig. 2b and Supplementary Figure 1A, right panel), which demonstrated the specificity of this antibody for $\beta$-DG detection. We hypothesized that the $\sim 30 \mathrm{kDa}$ band correspond to the ICD of $\beta$-DG generated by $\gamma$ secretase cleavage as has been described previously ${ }^{3,13,16}$. Compatible with this assumption, lysates from cells treated with DAPT ( $\gamma$-secretase inhibitor) resulted in a dosedependent decrease in $\beta$-DG ICD levels that paralleled with 


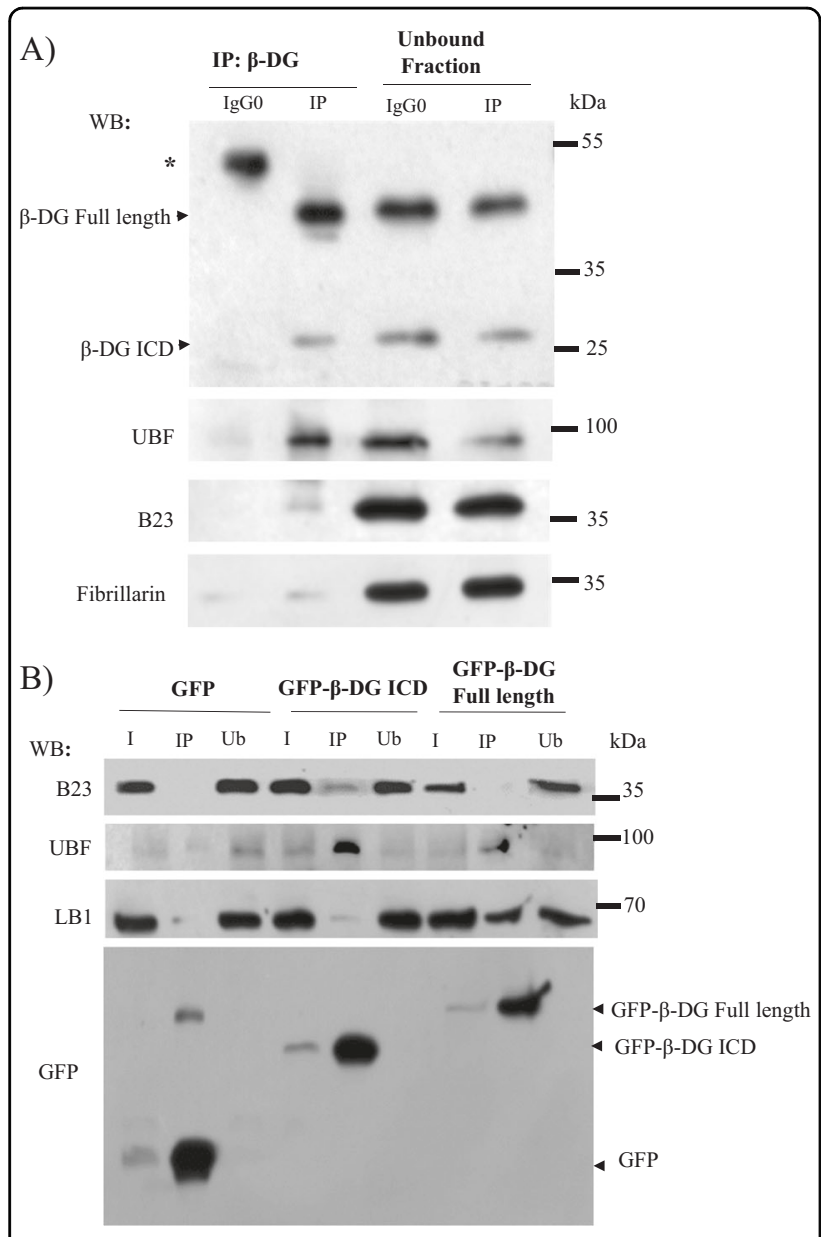

Fig. $3 \beta$-DG ICD interacts with the nucleolar proteins UBF and B23. a $C 2 C 12$ cell lysates were subjected to immunoprecipitation (IP) using anti- $\beta-D G$ antibody (Mandag) and the precipitated proteins were subsequently analyzed by western blotting using primary antibodies against $\beta-D G, U B F, B 23$, or fibrillarin. $\mathbf{b}$ Lysates from cells transiently expressing GFP- $\beta$-DG full-length, $\beta$-DG ICD, or GFP alone were subjected to immunoprecipitation using the GFP-Trap system, and the captured proteins were analyzed by western blotting using antibodies against B23, UBF, lamin B1 (LB1), and GFP. a, b Ub, unbound proteins, IP immunoprecipitated fraction, $\lg G 0$, nonspecific antibody. Input corresponds to $10 \%$ of protein lysates prior to immunoprecipitation

dose-dependent reduction of the intracellular domain of Notch (NICD), a well-characterized $\gamma$-secretase substrate (Fig. 2c). Collectively these data support the idea that the $\gamma$-secretase-derived cleavage fragment of $\beta$-DG $(\sim 30 \mathrm{kDa})$, named hereafter as $\beta$-DG ICD, is targeted to the nucleolus where it possibly has a role in regulating nucleoli structure/ function.

\section{$\beta$-DG ICD interacts with UBF and B23}

Colocalization of $\beta$-DG with nucleolar proteins even after induced nucleolar disruption (Fig. 1b), suggests their physical interaction. Consistent with this notion, UBF and traces of B23 but not fibrillarin were recovered in complex with $\beta$-DG after immunoprecipitation (IP) of C2C12 lysates with anti- $\beta$-DG antibody (Fig. 3a). None of the nucleolar proteins were immunoprecipitated using nonspecific IgG antibodies. Because anti- $\beta$-DG antibody immunoprecipitated both $\beta$-DG full-length and $\beta$-DG ICD, we wondered what form is bound to nucleolar proteins. To approach this, $\mathrm{C} 2 \mathrm{C} 12$ cells were transiently transfected to express GFP- $\beta$-DG full-length or GFP- $\beta$ DG ICD and subjected to GFP-based IP assays. Both UBF and B23 were found preferentially bound to GFP- $\beta$-DG ICD, with UBF interaction predominant over that with B23 (Fig. 3b). GFP alone interacted with neither B23 nor UBF, while lamin B1 ( $\beta$-DG nuclear partner) was bound to GFP- $\beta$-DG full-length but not GFP- $\beta$-DG ICD, demonstrating the specificity of GFP-Trap assays.

\section{Silencing of DG disrupts nucleolar morphology and decreases B23 and UBF levels}

To elucidate whether nucleolar localization of $\beta$-DG is physiologically relevant, the impact of knocking down of $\beta$-DG expression on nucleolar structure and expression of nucleolar proteins was examined. Significant reduction of dystroglycan mRNA levels and the consequent decrease in $\beta$-DG full-length and $\beta$-DG ICD levels were observed upon stably transfection of $\mathrm{C} 2 \mathrm{C} 12$ cells with a vector expressing a short hairpin RNA against DAG1 gene (DG shRNA), compared to cells expressing an unspecific shRNA (control shRNA) (Fig. 4a, b). Remarkably, the depletion of $\beta$-DG resulted in decreased proteins levels of B23 (80\%), fibrillarin (30\%), and UBF (60\%) (Fig. 4b). Such effects were accompanied by a clear alteration in nucleolar morphology; while control shRNA cells contain numerous relatively small nucleoli, $\beta$-DG-depleted cells exhibited fewer larger and more amorphous nucleoli, as shown by immunostaining for UBF and B23 (Fig. 4c, d) and quantification of nucleolar area (right panels).

\section{$\beta$-DG binds to the rDNA promoter to possibly regulate rRNA expression}

Because knockdown of $\beta$-DG resulted in decreased levels of UBF, a key component of the RNA polymerase I preinitiation complex in rRNA transcription, we sought to determine the expression of $28 \mathrm{~S}$ and $18 \mathrm{~S}$ pre-rRNAs in $\beta$-DG knockdown cells by quantitative RT-PCR (Figure 4a). $\beta$-DG knockdown cells exhibited an $\sim 40 \%$ decrease in $18 \mathrm{~S}$ levels, while $28 \mathrm{~S}$ expression showed a slight but significant increase, compared with control shRNA (Fig. 5a). To provide insight into the mechanism by which $\beta$-DG depletion influences rDNA gene expression, we analyzed whether $\beta$-DG is physically associated with the rDNA promoter. Chromatin was immunoprecipitated from wild-type and DG knockout (negative control) $\mathrm{C} 2 \mathrm{C} 12$ cells, using $\beta$-DG or nonspecific IgG 


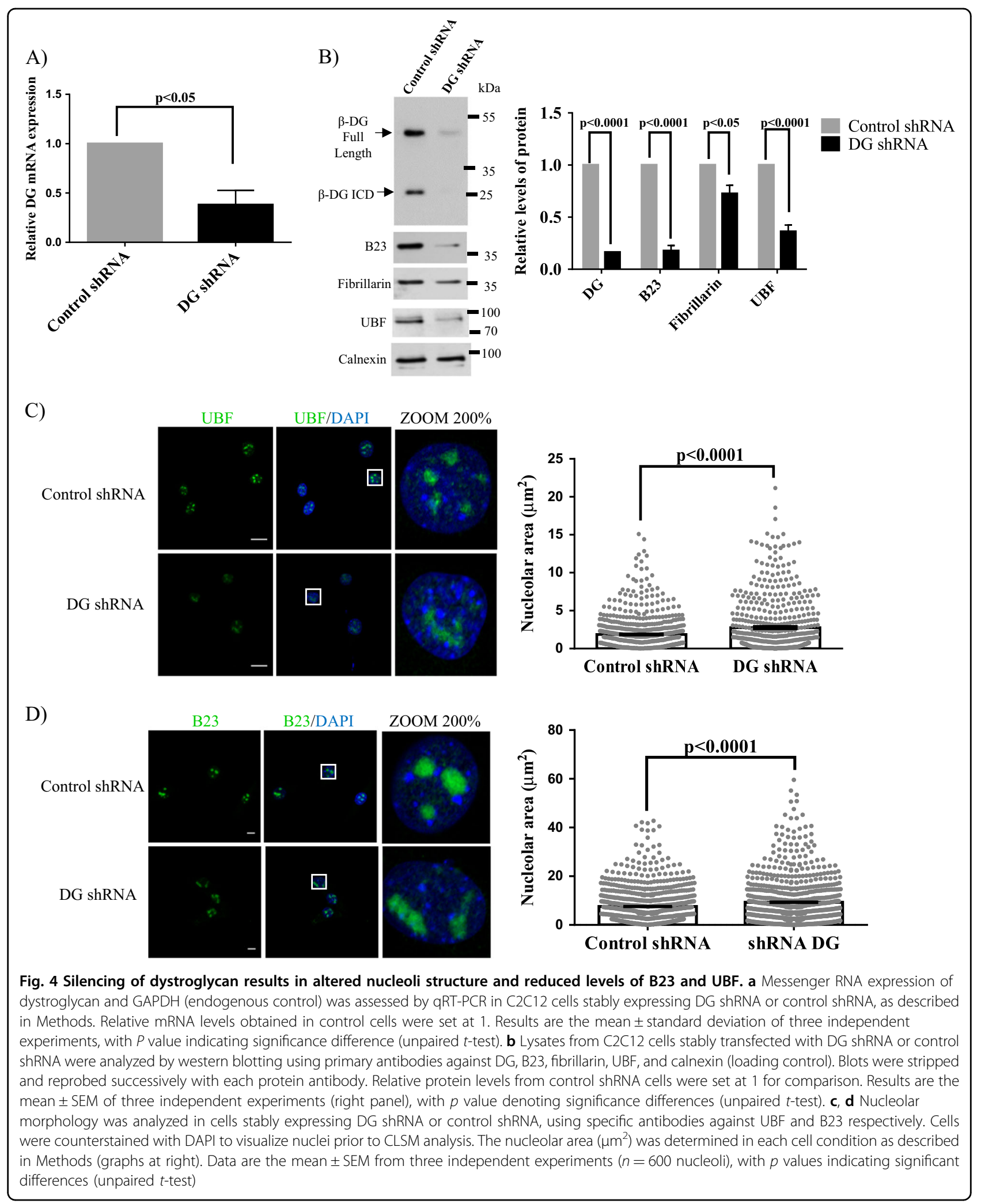

antibodies; moreover, ChIP assays using RNA polymerase I (Pol I) antibodies were performed in parallel (positive control). Then, rDNA was amplified using primers specific for the rDNA promoter, $5.8 \mathrm{~S}$ or intergenic spacer (IGS) regions. ChIP assays revealed the presence of $\beta$-DG in the $5.8 \mathrm{~S}$ and IGS regions, while Pol I was found to 


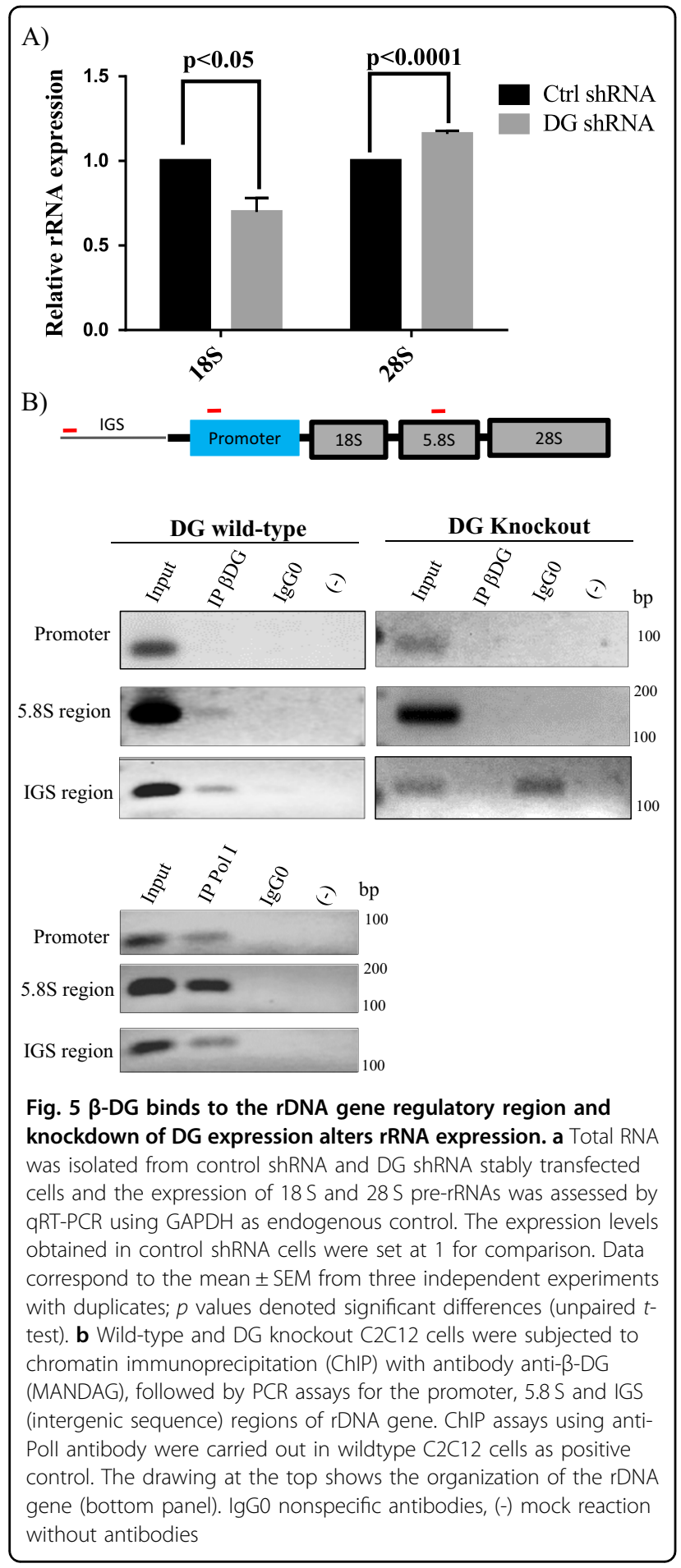

occupy all three regions of the rDNA (Fig. 5b). As expected, no PCR amplification was detected upon ChIP assays on DG knockout cells (right panel), which demonstrated the specificity of Mandag antibody for immunoprecipitating $\beta$-DG from chromatin. Overall these data suggest that $\beta$-DG may modulate rRNA transcript expression through its binding to the rDNA regulatory region.

\section{Nucleolar stress-induced $\beta$-DG ICD cleavage correlates with impaired ribosome biogenesis}

In an effort to understand the potential role of $\beta$-DG ICD in the nucleolus, we investigated whether $\beta$-DG ICD cleavage is induced by nucleolar stress. $\mathrm{C} 2 \mathrm{C} 12$ cells were subjected to different kind of stresses, namely oxidative stress, acidosis, and UV irradiation, and effectiveness of treatments was monitored by $\mathrm{p} 53$ activation. Interestingly, the ratio of $\beta$-DG ICD/full-length $\beta$-DG was augmented in response to all treatments with concomitant decrease in UBF content, with $\mathrm{H}_{2} \mathrm{O}_{2}$ and UV being the most effcient inductors (Fig. 6a, b). As expected, $\mathrm{H}_{2} \mathrm{O}_{2}$-induced nucleolar stress resulted in nucleolar segregations, with a formation of UBF-stained nucleolar caps at the periphery of B23-stained nucleoli (Supplementary Figure 3), which elicited ultimately downregulation of $45 \mathrm{~S}$ rRNA expression (Fig. 6c) and abnormal ribosomal profiling characterized by decreased monosomes and polysome absorbance peaks (Fig. 6d). We hypothesized that augmented $\beta$-DG ICD levels could be reflected in a higher binding activity to the rDNA promoter; consistent with this idea, occupancy of the three $\mathrm{rDNA}$ regulatory regions by $\beta$-DG markedly increased after $\mathrm{H}_{2} \mathrm{O}_{2}$ treatment, as revealed by ChIP-qPCR assays (Fig. 6e).

\section{Overexpression of $\beta$-DG ICD impairs ribosomal biogenesis by suppressing UBF function}

To analyze directly the implication of $\beta$-DG ICD in ribosome biogenesis, we stably transfected $\mathrm{C} 2 \mathrm{C} 12$ cells with a GFP- $\beta$-DG ICD vector, to mimic high levels of the cleavage fragment. GFP- $\beta$-DG ICD localization was restricted to the nucleus showing homogenous distribution throughout the nucleoplasm, with less intense staining in nucleoli (Fig. 7a). Remarkably, the significant number of GFP- $\beta$-DG ICD-transfected cells exhibited mislocalization of UBF foci to the cytoplasm, compared to GFP alone ( $50 \%$ and $20 \%$, respectively), while the nucleolar distribution of B23 remained unaltered (Fig. 7a, bottom panel and right panel). Impaired nucleolar localization of UBF due to exogenous $\beta$-DG ICD expression was confirmed by transfecting FLAG-tagged $\beta$-DG ICD (Supplementary Figure 4, top rows). Furthermore, overexpression of GFP- $\beta$-DG ICD resulted in decreased levels of UBF with no effect on B23, compared to GFP alone (Fig. 7b and right panel). We have demonstrated previously that the phosphorylation of $\beta$-DG at Tyr890 is not only a signal for the proteolysis and internalization of dystroglycan ${ }^{3,16,22}$ but also acts to target dystroglycan to the nucleus ${ }^{10}$. We considered therefore whether phosphorylation of $\beta$-DG ICD at the PPxY motif $\left(\mathrm{Tyr}^{890}\right)$ plays a role in UBF mislocalization. Thus, FLAG- $\beta$-DG ICD 


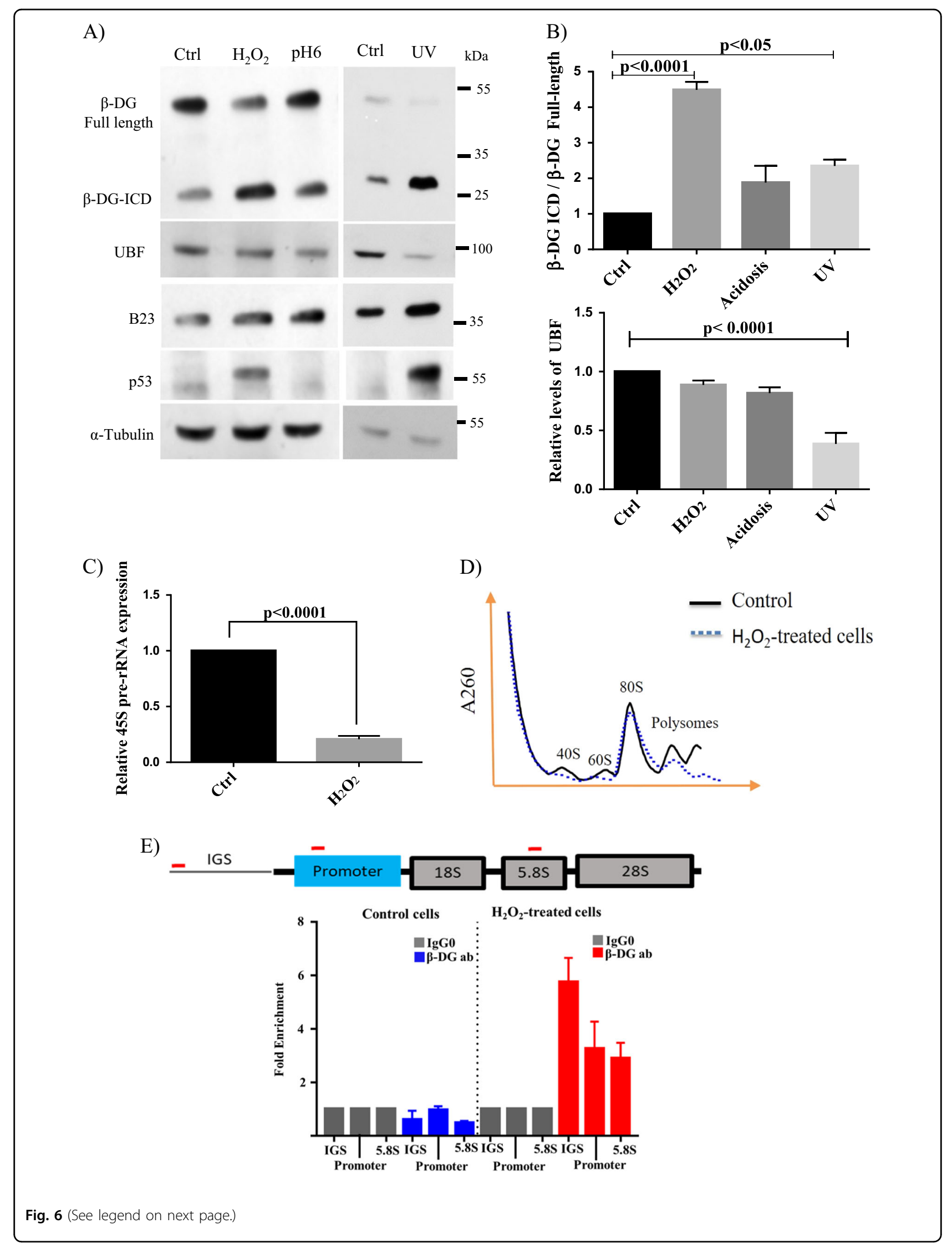


(see figure on previous page)

Fig. 6 Nucleolar stress triggers $\beta$-DG ICD and disturbs rRNA expression and ribosome profile. a Lysates from control (ctrl, untreated) cells or cells induced to nucleolar stress response by $\mathrm{H}_{2} \mathrm{O}_{2}$ treatment, UV irradiation or acidosis ( $\mathrm{pH}$ 6) (see Methods for details) were analyzed by western blotting using specific antibodies against $\beta-D G, U B F, B 23, p 53$, and a-tubulin. $\mathbf{b}$ Quantification of $\beta-D G$ ICD/ $\beta$-DG full-length ratio and UBF levels was carried out using a-tubulin as loading control. Results correspond to the mean \pm SEM of three independent experiments with $p$ values denoting significant differences (ordinary one-way ANOVA). c The $45 \mathrm{~S}$ rRNA precursor expression was assessed by qRT-PCR using GAPDH as endogenous control. The expression levels obtained in control cells were set at 1 for comparison. Data correspond to the mean \pm SEM from three independent experiments with duplicates; $p$ values denoted significant differences (unpaired $t$-test). $\mathbf{d}$ Ribosome profiling from control and $\mathrm{H}_{2} \mathrm{O}_{2}$-treated cells are shown. e Chromatin immunoprecipitation assays on control and $\mathrm{H}_{2} \mathrm{O}_{2}$-treated $\mathrm{C} 2 \mathrm{C} 12$ cells were performed, with specific antibody against $\beta$-DG (Mandag), followed by SYBR green-based qPCR assays for the promoter, $5.8 \mathrm{~S}$ and IGS (intergenic sequence) regions of rDNA gene. Scheme of rDNA gene regulatory regions is shown at the top

variants that either mimic (Y890E) or block (Y890A) the $\mathrm{Tyr}^{890}$ phosphorylation were analyzed for UBF localization. Similar percentage of transfected cells showing UBF outside of the nucleus were observed between $\beta$-DG ICD FLAGY890A and $\beta$-DG ICD-FLAGY890E; thus, overexpression of $\beta$-DG ICD resulted in UBF mislocalization irrespective of a charged residue at residue 890 that mimics phosphorylation (Supplementary Figure 4). We hypothesized that decreased expression/mislocalization of UBF through $\beta$-DG ICD overexpression would ultimately impact rRNA expression. Consistent with this idea, an $\sim 50 \%$ decrease in $45 \mathrm{~S}$ rRNA and $28 \mathrm{~S}$ but not $18 \mathrm{~S}$ was found in cells stably overexpressing $\beta$-DG ICD, compared with those expressing GFP alone (Fig. 8a). To ascertain whether $\beta$-DG ICD overexpression influences Pol I transcription, functional rRNA promoter reporter assays were carried out in $\beta$-DG ICD stably transfected cells, using a vector that expresses Firefly luciferase under the control of the mouse rRNA promoter and a vector that expresses Renilla luciferase to normalize transfection efficiency. Pol I promoter activity was found to decrease by $40 \%$ in GFP$\beta$-DG ICD-transfected, compared with those with GFP alone (Fig. 8b). Because the rRNA content is a crucial point of regulation for ribosome biogenesis, we hypothesized that decreased $40 \mathrm{~S}$ and $60 \mathrm{~S}$ levels would impact the ribosome profile. Consistent with this notion, altered ribosome profiles devoid of the peaks corresponding to free $40 \mathrm{~S}$ and $60 \mathrm{~S}$ ribosomal subunits were observed in cells expressing $\beta$-DG ICD (Fig. 8c). Such impairment in rRNA expression and polysome profiling ultimately leads to defective proliferative capacity of $\beta$-DG ICD overexpressing cells, as shown by MTT-based proliferation assays (Fig. 8d). Collectively these data indicate that $\beta$-DG ICD acts as negative regulator of rRNA expression by affecting both the levels and transcriptional activity of UBF.

\section{Discussion}

$\beta$-DG is a key component of both PM and NE, acting as a platform for the proper anchorage of organelle-specific protein assemblies. At the PM $\beta$-DG modulates adhesion/ signaling by connecting extracellular matrix proteins with the actin-based cytoskeleton ${ }^{5,7}$, while in the nucleus $\beta$-DG interacts with the NE proteins emerin and lamins $\mathrm{A} / \mathrm{C}$ and $\mathrm{B} 1$ to regulate nuclear structure and function ${ }^{11,12}$. This functional diversity could be wider than originally thought, due to the potential function of $\beta$-DG proteolytic fragments. Recent in vitro and in vivo evidence showed that $\beta$-DG undergoes two successive and possibly coordinate proteolytic cleavages that result in the liberation of the intracellular domain (ICD) into the cytosol; first matrix metalloproteinases, MMP-2 and MMP-9 cleave the extracellular domain of $\beta-\mathrm{DG}^{23}$ and create a membrane-tethered intermediate that is subsequently processed by $\gamma$-secretase, a PM-embedded protease complex, to render a final cleavage product that approximates the entire $\mathrm{ICD}^{21}$. Except for cell density ${ }^{21}$, other cellular stimuli inducing $\beta$-DG ICD release as well as the physiological consequences of such processing event are largely unknown. In this study we showed that $\beta$-DG ICD associates to nucleoli and its cleavage is promoted by the induction of a different kind of nucleolar stresses. We also ascribed for the first time a role for $\beta$-DG ICD in regulating rRNA transcription through negative regulation of the expression and transcriptional activity of UBF, in the context of the response to nucleolar stress.

We show herein that $\beta$-DG colocalizes and interacts with the key nucleolar proteins B23 and UBF, and, based on the converging redistribution of $\beta-D G$ with B23, fibrillarin, or UBF in response to both actinomycin- and DRB-induced nucleoli disorganization, we hypothesized that $\beta$-DG participates in the functional plasticity of nucleoli. Interestingly, cell fractionation experiments revealed the presence of $\beta$-DG ICD but not $\beta$-DG fulllength in the nucleolar fraction of $\mathrm{C} 2 \mathrm{C} 12$ cells; however, GFP-based IP experiments revealed that both $\beta$-DG ICD and $\beta$-DG full-length are able to bind UBF. Because fulllength $\beta$-DG is an NE protein associated with nuclear lamin and because the interaction of intranuclear filaments of lamins with nuclear compartments (including nucleoli) has been well established ${ }^{24-26}$ it is possibly that IP of $\beta$-DG full-length pulled down a nuclear 


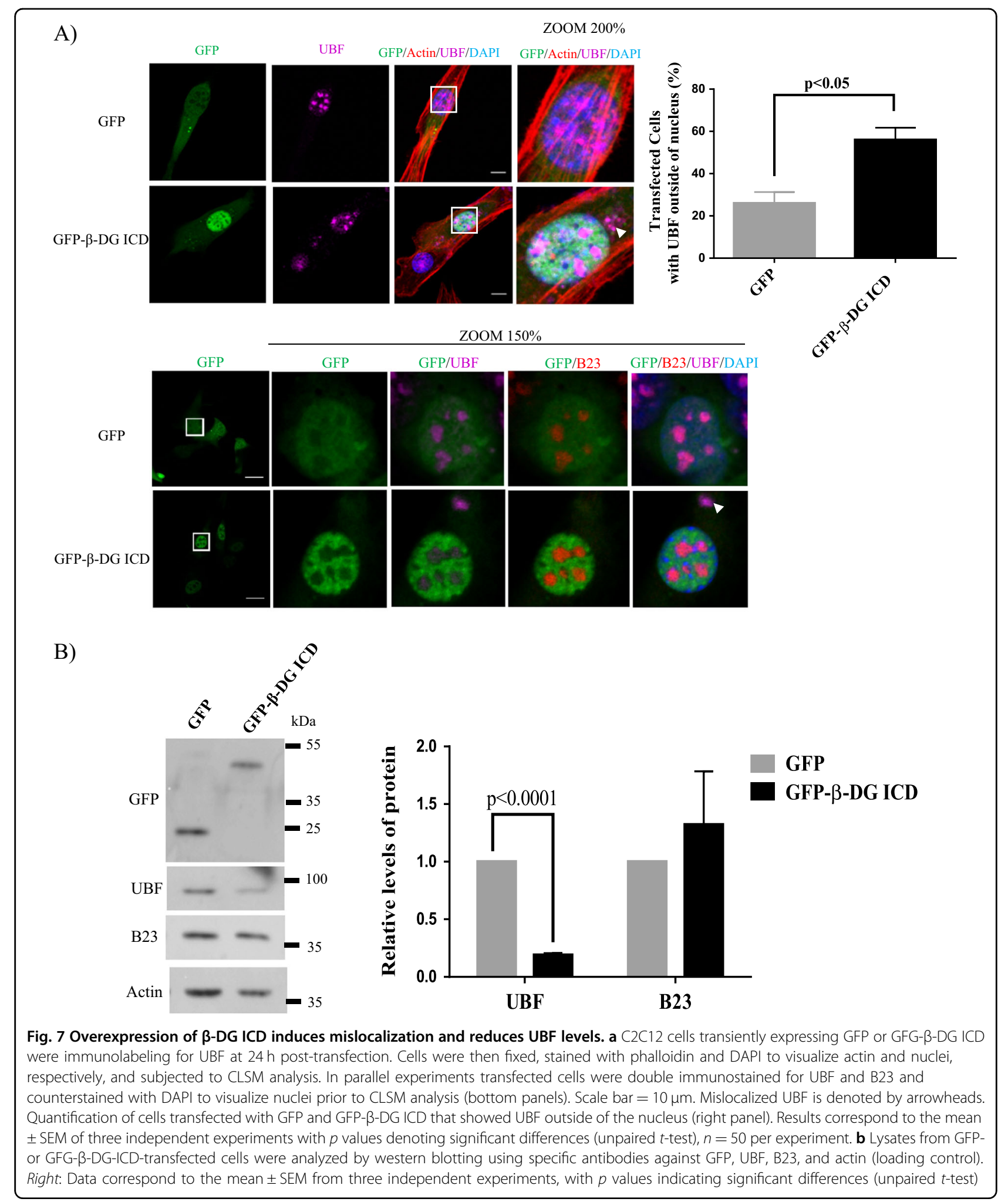

macromolecular complex containing NE (lamin B1) and nucleolar (UBF) proteins. The trafficking pathway underlying nucleolar targeting of $\beta$-DG ICD remains to be deciphered. Full-length $\beta$-DG is translocated to the nucleus through recognition of its NLS by importins $\alpha 2 / \beta 1^{9}$, therefore it is likely that $\beta$-DG ICD enters the nucleus by virtue of the NLS that is still present in the cleaved fragment, or alternatively by passive diffusion 


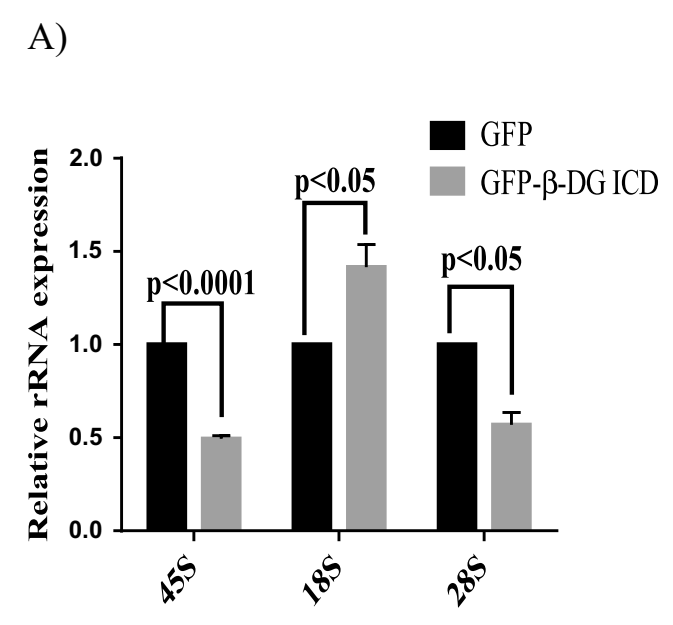

C)

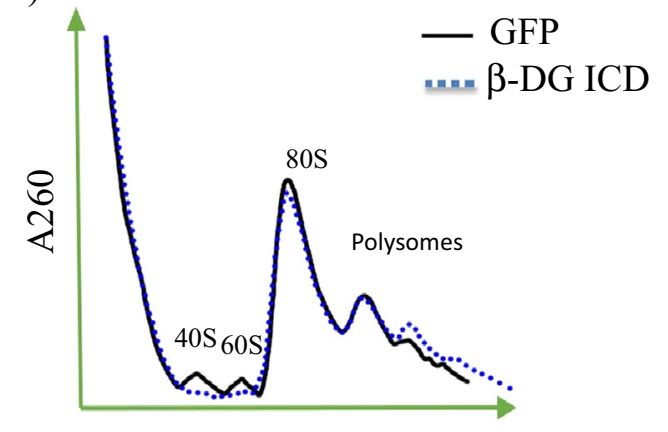

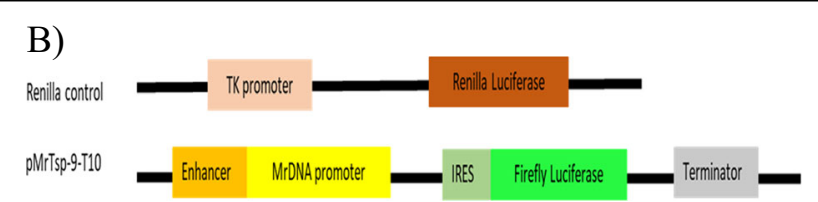

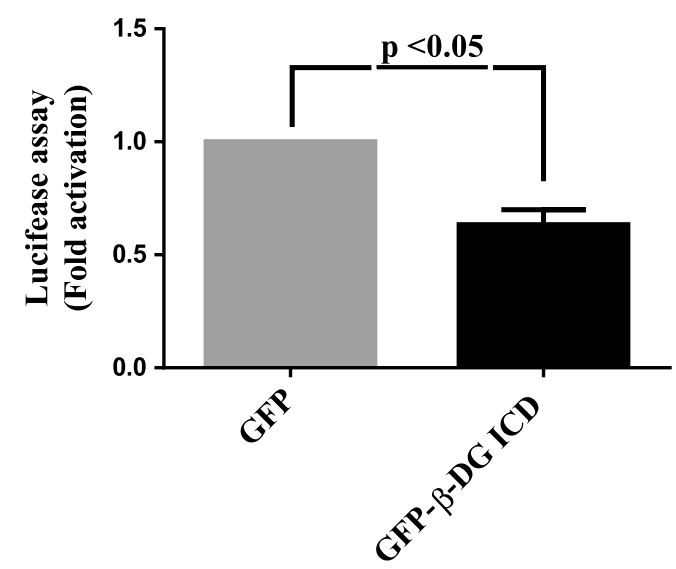

D)

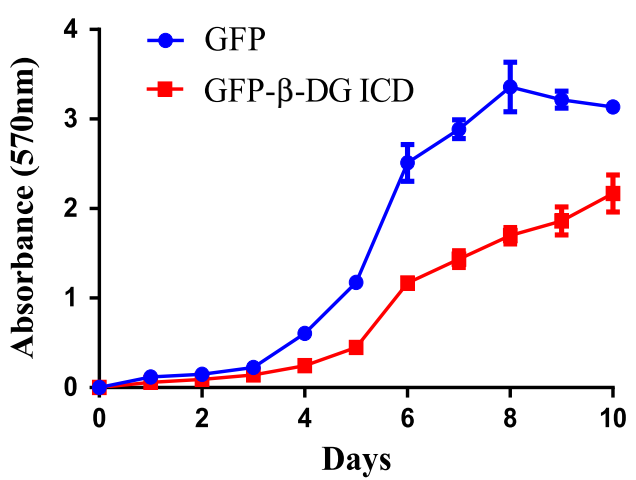

Fig. 8 Exogenous expression of $\beta$-DG ICD impairs ribosome biogenesis by affecting transcriptional activity of UBF. C2C12 cells were transfected to stably express GFP- $\beta$-DG ICD or GFP alone (empty vector). a The expression of $45 \mathrm{~S}$, $18 \mathrm{~S}$, and $28 \mathrm{~S}$ rRNAs was analyzed in the transfected cell cultures, using GAPDH as endogenous control. b Schematic representation of the mouse rDNA promoter construct (pMrTsp-9-T10) and Renilla luciferase control vector is shown at the top. Cell cultures stably expressing GFP- $\beta$-DG ICD or GFP alone were co-transfected with both luciferase reporter constructs and transcriptional activities were estimated after incubation for $48 \mathrm{~h}$, as described in Methods. Control condition obtained in cells transfected with GFP alone was set at 1 for comparison. Data represent mean \pm SEM of three independent experiments; $p$ values denote a significant difference (unpaired $t$-test). c The ribosomal gradient profiles obtained from transfected cell cultures are shown. $\mathbf{d}$ Cell proliferation of the stably transfected cell cultures was monitored over a 10-day period using the MTT assay. Data represent mean \pm SEM of three independent experiments

through the nuclear pore complex (NPC), because its molecular mass $(<30 \mathrm{kDa})$ is clearly below the NPC permissive $\operatorname{size}^{27}$. No obvious nucleolar localization signal is found in $\beta$-DG ICD, thus, its nucleolar accumulation might be mediated by a retention mechanism via interaction with nucleolar components. Supporting this idea, $\beta$-DG ICD was found to interact with B23, a shuttle protein that transports cargos between the cytoplasm and the nucleolus and mediates nucleolar retention of other proteins $^{28}$. Furthermore, binding of $\beta$-DG to the rDNA gene regulatory region (see below) could serve to anchor $\beta$-DG ICD to nucleoli too. Owing to the main contribution of nucleoli in ribosome biogenesis ${ }^{16}$, we wondered whether $\beta$-DG is involved in this process. We provide here solid evidence supporting this hypothesis: first, $\beta$-DG interacts with UBF, an HMG box-containing protein that binds directly with rDNA and plays an important role in the recruitment of SL1 (selectivity factor 1) and Pol I to the rRNA promoter to constitute the Pol I preinitiation machinery complex ${ }^{29}$; second, ChIP assays with anti- $\beta$-DG antibody demonstrated $\beta$-DG recruitment to the rDNA $5.8 \mathrm{~S}$ and IGS regulatory regions; and third, DG silencing resulted in reduced UBF levels, decreased $18 \mathrm{~S}$ pre-rRNA expression but not $28 \mathrm{~S}$ pre-rRNA 


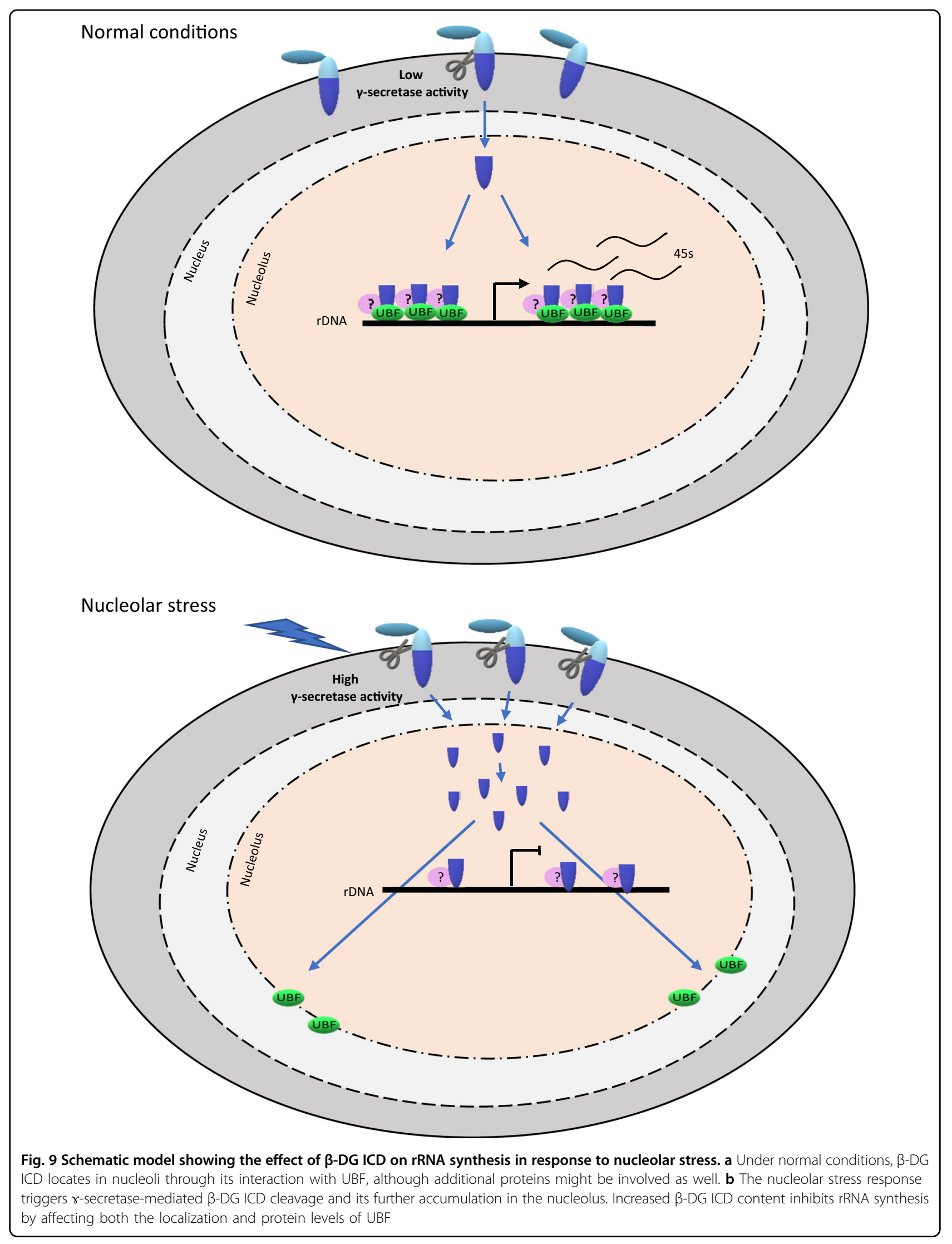


expression, and aberrant nucleolar morphology. Discordant expression between $28 \mathrm{~S}$ and $18 \mathrm{~S}$ rRNAs is intriguingly. Even though both $28 \mathrm{~S}$ rRNA and $18 \mathrm{~S}$ rRNA are originated from $45 \mathrm{~S}$ rRNA precursor, their processing/maturation pathways differ from each other, and each one is assisted by specific exo and endoribonucleasas ${ }^{30}$. Therefore, we argue that aside from its effect on rDNA basal transcription machinery (as shown here), $\beta$-DG ICD might modulate processing pathways of $18 \mathrm{~S}$ rRNA and $28 \mathrm{~S}$ rRNA differentially by indirect mechanisms. Additional experiments are needed to clear this issue.

The nucleolus is a central hub for orchestrating stress response, with downregulation of rRNA synthesis taking place as a part of ribosome biogenesis surveillance ${ }^{31}$, furthermore, numerous proteins that functions are not generally ascribed to ribosome biogenesis are recruited to the nucleolus in response to environmental stimuli ${ }^{32}$. Therefore, we ascertained whether $\beta$-DG ICD cleavage is coupled to the response to nucleolar stress. Remarkably, triggers of $\beta$-DG ICD cleavage by Notch signaling activation occurred in response to different nucleolar stressor treatments, including oxidative stress, acidosis, and UV irradiation. Supporting a role for $\beta$-DG ICD in the response to nucleolar stress, $\beta$-DG ICD overexpression was sufficient to elicit several features of nucleolar stress, including mislocalization and decreased levels of UBF, repression of rRNA transcription, altered ribosome profile, and decreased cell proliferation.

The results raise the question of how $\beta$-DG ICD exerts a negative regulation on rDNA expression. $\beta$-DG lacks DNA-binding motifs or enzymatic activity and is considered as a scaffold protein, due to the presence of protein modules supporting interactions with diverse proteins (e.g. SH3, SH2, and WW domains) ${ }^{5}$. Therefore, we postulate that binding of $\beta$-DG ICD to UBF may lead to mislocalization and decreased levels of the latter protein, possibly by altering its stability, thereby interfering with the assembly of the Pol I initiation complex and the subsequent UBF-dependent activation of rDNA transcription (Fig. 9). Because the occupancy of rDNA regulatory regions by $\beta$-DG increased in response to nucleolar stress, it is also possible that $\beta$-DG ICD exerts its suppressive effect by displacing UBF from the Pol I transcription complex, which is consistent with mislocalization of UBF to the nucleolar periphery and cytoplasm that was observed in $\mathrm{H}_{2} \mathrm{O}_{2}$-treated cells. Further ChIP assays to ascertain whether $\beta$-DG and UBF coexist or not in the rDNA promoter region under nucleolar stress conditions are needed to solve this question. Furthermore, since $\beta$-DG has multiple partners in the nucleus, the existence of an indirect mechanism by which $\beta$-DG ICD represses UBF activity cannot be ruled out. The implication of $\beta$-DG ICD in rDNA expression could be envisioned as an extension of the homeostatic role of
$\beta$-DG, where induction of ICD cleavage and its further targeting to the nucleolus in response to environmental stress, like oxidative stress, acts as a protective response to inhibit rDNA transcription and further proliferation of damaged cells.

In summary, our data are compatible with the paradigm that $\beta$-DG ICD functions as a negative regulator of rRNA transcription by impeding the transcriptional activity of $\mathrm{UBF}$, as a part of the nucleolar stress response mechanisms that are activated under physiologically relevant stress conditions. Thus, in addition to its roles as PM and $\mathrm{NE}$ signaling scaffold, $\beta$-DG should be regarded as a regulator of Pol I transcription in the nucleolus.

\section{Materials and methods}

\section{Cell culturing and treatments}

Mouse $\mathrm{C} 2 \mathrm{C} 12$ myoblasts (ATCC ${ }^{\circ}$ CRL-1772') were grown as previously (Vásquez-Limeta, et al 2014). Generation of C2C12-derivative DG knockout cell lines with the CRISP/Cas9 system will be published elsewhere. For nucleoli disorganization treatments, cells were treated for $3 \mathrm{~h}$ with $0.01 \mu \mathrm{g} / \mathrm{ml}$ Act D (SigmaAldrich, St Louis, Missouri) or $25 \mu \mathrm{g} / \mathrm{ml}$ DRB (5,6 dichloro-1-d-ribofuranosylbenzimidazole; SigmaAldrich, St Louis, Missouri) or vehicle alone (DMSO), prior to confocal laser scanning microscopy (CLSM) analysis. The $\gamma$-secretase inhibitor $\mathrm{N}-(\mathrm{N}-(3,5$-difluorophenacetyl)-L-alanyl). S-phenylglycine t-butyl ester (DAPT; Sigma-Aldrich, St Louis, Missouri) was used at $10 \mu \mathrm{M}$ for $24 \mathrm{~h}$. For induction of the nucleolar stresses response, cells were cultured in DMEM supplemented with serum adjusted to $\mathrm{pH} 6$, treated with $1.4 \mathrm{mM} \mathrm{H}_{2} \mathrm{O}_{2}$ (7722-84-1,Sigma-Aldrich) for $4 \mathrm{~h}$ or subjected to UV radiation using a pulse of $20 \mathrm{~J} / \mathrm{cm}^{2}$ each $24 \mathrm{~h}$ for 2 days. For nuclease digestion assays, cells grown on coverslips were treated with either $100 \mu \mathrm{g} / \mathrm{ml}$ protease-free RNase A in CSK buffer $(10 \mathrm{mM}$ Pipes $\mathrm{pH} 6.8,100 \mathrm{mM} \mathrm{NaCl}$, $30 \mathrm{mM}$ sucrose, $3 \mathrm{mM} \mathrm{MgCl} 2,1 \mathrm{mM}$ EGTA, $0.5 \%(\mathrm{v} / \mathrm{v})$ Triton X-100) for $40 \mathrm{~min}$ at $37^{\circ} \mathrm{C}$ or with $200 \mu \mathrm{g} / \mathrm{ml}$ protease-free DNase I in PBS with $5 \mathrm{mM} \mathrm{MgCl}_{2}$ for $1 \mathrm{~h}$ at $37^{\circ} \mathrm{C}$, then the cells were fixed with PFA $4 \%$ and immunolabeled using primary antibodies and the corresponding fluorochrome-conjugated secondary antibodies. Negative control experiments were carried out by incubating cells only with CSK buffer (RNase) or PBS with $5 \mathrm{mM} \mathrm{MgCl}{ }_{2}$ (DNase) prior to fixation.

\section{Plasmids and transfection}

The expression vectors Flag- $\beta$-DG ICD WT, Flag- $\beta$-DG ICDY890E, and Flag- $\beta$-DG ICDY890A were generated by PCR amplification using DGWT-DG, DGY890E-GFP, and DGY890A-GFP plasmids as template, respectively ${ }^{10}$. The cDNA sequence encoding the intracellular domain of $\beta$-DG (ICD, amino acids 774-895) was amplified using an 
M-MLV reverse transcriptase coupled to a high-fidelity polymerase ( $P f u$ turbo; Strategene) and primers containing Hind III and EcoRI restriction sites. Forward primer was 5 '-CCTAAGCTTTATCGCAAGAAGAGGAAGGG C-3' and the respective reverse primers were $5^{\prime}$-CTGAAT TCTTAAGGGGGAACATACGGAGGG-3' (ICD WT), 5'-CTGGAATCCTTAAGGGGGAACCTCCGGAGGG-

$3^{\prime}$ (ICD Y890E mutation), and 5'-CTGAATTCTTAAG GGGGAACTGCCGGAGGG-3' (ICD Y890A mutation). PCR products were double digested with Hind III and EcoRI and cloned into the Hind III-EcoRI digested pFlagCMV-10 vector. The integrity of the constructs was confirmed by DNA sequencing. Transfection was performed following supplier's recommendations. Briefly, cells seeded onto glass coverslips were incubated overnight and then transfected with $3 \mu \mathrm{g}$ of the corresponding vector premixed with $3 \mu \mathrm{l}$ of Lipofectamine 2000 (Invitrogen, Carlsbad, CA, USA). Transiently transfected cells were analyzed at $24 \mathrm{~h}$ post-transfection. When indicated, cells were stably transfected by culturing them for 12 days in the presence of $2 \mu \mathrm{g} / \mathrm{ml}$ puromycin (Invitrogen) or for 5 days in the presence of $800 \mu \mathrm{g} / \mathrm{ml}$ gentamicin (G418), prior to being used for further experiments. For knockdown experiments, cells were stably transfected with psi$\mathrm{mH} 1$ vector expressing a small interfering RNA (RNAi) specific for mouse DAG1 gene or a scrambled RNAi, as negative control (GeneCopoeia, Inc., Rockville, MD). For overexpression analysis, cells were stably transfected with GFP constructions as previously reported ${ }^{9}$.

\section{Antibodies}

The following anti- $\beta$-DG primary antibodies were used: rabbit polyclonal antibodies G5 (Royuela et al, 2001) and Dystroglycan pTyr892 (Ilsley et al, 2002); goat polyclonal antibody C20 (Santa Cruz Biotechnology, CA), and mouse monoclonal antibodies MANDAG2 ${ }^{33}$ and 7D11 (Santa Cruz). Rabbit polyclonal antibodies anti-B23 (C19-R), anti-Nup62 (H-122), anti-calnexin (H70), anti-fibrillarin (Ab5821), anti-GFP (sc8334) and mouse monoclonal antibodies anti-UBF (F9), anti-B23 (NPM1-FC-61991) (anti-RNA polymerase I (sc-46699), anti-lamin B1 (Ab16048), anti-and anti-RPA(sc-46699), and $\alpha$-Tubulin (sc-32293) were purchased from Santa Cruz Biotechnology, CA, USA. Rabbit polyclonal anti-Flag (2368) and rabbit monoclonal anti-Notch1 (4147) antibodies were acquired from cell signaling, while mouse monoclonal anti-actin antibody was a gift from Dr. Manuel Hernández (CINVESTAV, Mexico City).

\section{Immunofluorescence and confocal microscopy analysis}

Cells grown on coverslips were fixed with $4 \%$ paraformaldehyde for $10 \mathrm{~min}$ in PBS, permeabilized with $0.2 \%$ Triton X-100-PBS, blocked with $0.5 \%$ fetal bovine serum and $3 \%$ bovine serum albumin (BSA) in PBS and incubated overnight at $4{ }^{\circ} \mathrm{C}$ with the appropriate primary antibodies. The following day, cells were washed with $0.2 \%$ Triton X100-PBS for $5 \mathrm{~min}$ and then with PBS alone three times, prior to be incubated for $1 \mathrm{~h}$ at room temperature with the appropriate fluorochrome-conjugated secondary antibody. For double immunolabeled samples, this was followed by overnight incubation at $4{ }^{\circ} \mathrm{C}$ with corresponding primary antibodies and the next day, cells were incubated with secondary fluorochrome-conjugated antibodies. Where indicated F-actin was labeled using TRITC-conjugated Phalloidin (Sigma-Aldrich St. Louis, Mo. USA) diluted 1:500 in PBS for $10 \mathrm{~min}$ at room temperature. For nuclease digestion assays, cells grown on coverslips were treated with either $100 \mu \mathrm{g} / \mathrm{ml}$ protease-free RNase A in CSK buffer (10 $\mathrm{mM}$ Pipes $\mathrm{pH}$ 6.8, $100 \mathrm{mM} \mathrm{NaCl}, 30 \mathrm{mM}$ sucrose, $3 \mathrm{mM}$ $\mathrm{MgCl}_{2}, 1 \mathrm{mM}$ EGTA, $0.5 \%$ (v/v) Triton X-100) for $40 \mathrm{~min}$ at $37^{\circ} \mathrm{C}$ or with $200 \mu \mathrm{g} / \mathrm{ml}$ protease-free DNase I in PBS with $5 \mathrm{mM} \mathrm{MgCl} 2$ for $1 \mathrm{~h}$ at $37^{\circ} \mathrm{C}$. Cells were then immunolabeled using primary antibodies and the corresponding fluorochrome-conjugated secondary antibodies. Finally, coverslip preparations were incubated for $20 \mathrm{~min}$ at room temperature with $0.2 \mu \mathrm{g} / \mathrm{ml}$ diamidino-2-phenylindole (DAPI; Sigma-Aldrich) for nuclei visualization, mounted on microscope slides with VectaShield (Vector Laboratories Inc. Burlingame, CA, USA) and further analyzed by CLSM (TCP-SP5, Leica Microsystems, Heidelberg, Germany) using a Plan Neo Fluor $63 \times(\mathrm{NA}=1.4)$ oil-immersion objective. Analyses of digitized images were carried out using ImageJ 1.62 software. The nucleolar area $\left(\mu \mathrm{m}^{2}\right)$ of 600 nucleoli was analyzed in maxima projection using 3D objects counter and the data were analyzed using Prism6 software. Manders overlap coefficients were calculated for double labeling inmunofluorescences, using red (Alexa $594 \mathrm{~nm}$ ) and green (FITC $488 \mathrm{~nm}$ ) channels and the ImageJ plugin JACoB. A line intensity scan analysis was performed by ROI manager Multiplot.

\section{Western blotting}

Cell lysates were electrophoresed on 10\% SDSpolyacrylamide gels and transferred onto nitrocellulose membranes (Hybond-Nb, Amersham Pharmacia, GE Healthcare, Bukinghamshire, UK). Membranes were blocked in TBST (100 mM Tris- $\mathrm{HCl} \mathrm{pH} 8.0,150 \mathrm{mM}$ $\mathrm{NaCl}, 0.5 \%$ (v/v) Tween-20) with low fat-dried milk and then incubated overnight at $4{ }^{\circ} \mathrm{C}$ with the appropriate primary antibodies. The specific protein signal was developed using the corresponding secondary antibodies and enhanced chemiluminescence western blotting detection system (ECL ${ }^{\mathrm{TM}}$; Amersham Pharmacia, GE Healthcare), according to the manufacturer's instructions.

\section{Cell fractionation}

Total cell extracts were obtained with lysis Buffer (10 $\mathrm{mM}$ Tris- $\mathrm{HCl} \mathrm{pH}$ 8, $30 \mathrm{mM} \mathrm{NaCl}, 0.2 \%$ Triton X-100, 4 
$\mathrm{mM} \mathrm{Na} \mathrm{Na}_{4} \mathrm{~V}, 50 \mathrm{mM} \mathrm{NaF}, 20 \mathrm{mM} \mathrm{Na} \mathrm{MoO}_{4}, 1 \mathrm{mM}$ PMSF, 1X complete protease inhibitor) sonicated three times at $3.5 \mu \mathrm{m}$ with $15 \mathrm{~s}$ bursts and analyzed by western blotting. Purification of the cytosolic, nuclear, and nucleolar fractions was performed as previously reported $^{34}$. A total amount of fifteen $100 \mathrm{~mm}$ dishes grown to $90 \%$ confluence were used; cells were washed twice with 1 $\mathrm{ml}$ of ice-cold PBS and collected by centrifugation at $15,000 \mathrm{rpm}$ for $15 \mathrm{~min}$ at $4{ }^{\circ} \mathrm{C}$. The pellet was resuspended in $1 \mathrm{ml}$ of buffer TM $(10 \mathrm{mM}$ Tris- $\mathrm{HCl} \mathrm{pH} 8,2 \mathrm{mM}$ $\mathrm{MgCl}_{2}, 25 \mathrm{mM} \mathrm{NaF}, 10 \mathrm{mM} \mathrm{Na}_{2} \mathrm{MoO}_{4}, 2 \mathrm{mM} \mathrm{Na}_{3} \mathrm{VO}_{4}, 1$ mM PMSF), supplemented with $1 \times$ complete protease inhibitor mixture (Roche Applied Science, Indianapolis, USA), and incubated on ice for $10 \mathrm{~min}$. Then, $2 \%$ Triton $\mathrm{X}-100-\mathrm{PBS}$ was added, and the homogenate incubated for $10 \mathrm{~min}$ on ice, transferred to a glass Dounce homogenizer, stroked 30 times with $B$ pestle, and centrifuged at 5,000 $\mathrm{rpm}$ for $15 \mathrm{~min}$ at $4{ }^{\circ} \mathrm{C}$. The supernatant was recovered as the cytosolic fraction and the nuclear pellet was resuspended in $1 \mathrm{ml}$ of buffer I ( $0.32 \mathrm{M}$ Sucrose, $3 \mathrm{mM} \mathrm{CaCl}_{2}$, $2 \mathrm{mM} \mathrm{Mg}\left(\mathrm{CH}_{3} \mathrm{COO}\right)_{2}, 0.1 \mathrm{mM}$ EDTA, $10 \mathrm{mM}$ Tris- $\mathrm{HCl}$ pH 8, 1 mM DTT, $0.5 \mathrm{mM}$ PMSF, 0.5\% (v/v) NP40) and 1 $\mathrm{ml}$ of Sucrose buffer II (2M Sucrose, $5 \mathrm{mM} \mathrm{Mg}$ $\left(\mathrm{CH}_{3} \mathrm{COO}\right)_{2}, 0.1 \mathrm{mM}$ EDTA, $10 \mathrm{mM}$ Tris- $\mathrm{HCl} \mathrm{pH} \mathrm{8.0,1}$ $\mathrm{mM}$ DTT, $0.5 \mathrm{mM}$ PMSF), and further purified by sucrose gradient centrifugation at $16,000 \mathrm{rpm}$ for $1 \mathrm{~h}$ at $4{ }^{\circ} \mathrm{C}$. The pellet was resuspended in $600 \mu \mathrm{l}$ of buffer III $(0.34 \mathrm{M}$ Sucrose, $1 \mathrm{mM} \mathrm{MgCl}$, $0.1 \mathrm{mM}$ EDTA, $10 \mathrm{mM}$ Tris- $\mathrm{HCl}$ pH 8.0, 1 mM DTT, 0.5 mM PMSF) and aliquots collected for extraction of nuclear and nucleolar proteins. For nuclear proteins, the aliquot was centrifuged at 1,000 rpm for $5 \mathrm{~min}$ at $4{ }^{\circ} \mathrm{C}$ and the pellet resuspended in $200 \mu \mathrm{l}$ of lysis buffer $(50 \mathrm{mM}$ Tris- $\mathrm{HCl} \mathrm{pH}$ 8.0, $150 \mathrm{mM} \mathrm{NaCl}, 1$ mM PMSF, 1\% (v/v) Triton X-100), supplemented with protease inhibitor cocktail and phosphatase inhibitors, sonicated 3 times at $4 \mu \mathrm{m}$ with $15 \mathrm{~s}$ bursts and $4 \mathrm{~min}$ on ice between intervals, and then pre-cleared at 13,000 rpm for $2 \mathrm{~min}$ at $4{ }^{\circ} \mathrm{C}$. For purification of nucleoli, the remaining $350 \mu \mathrm{l}$ aliquot was sonicated 5 times at $5 \mu \mathrm{m}$ with $30 \mathrm{~s}$ bursts and analyzed under a light microscope to ensure nucleoli integrity, prior to purification by centrifugation at $3,000 \mathrm{~g}$ for $20 \mathrm{~min}$ at $4{ }^{\circ} \mathrm{C}$ through a sucrose gradient, using buffer III and four volumes of Sucrose buffer IV (0.88 M Sucrose, $0.1 \mathrm{mM}$ EDTA, $10 \mathrm{mM}$ Tris- $\mathrm{HCl} \mathrm{pH}$ 8.0, $1 \mathrm{mM}$ DTT, $0.5 \mathrm{mM}$ PMSF). Finally, the pellet was washed in $500 \mu \mathrm{l}$ of buffer III and centrifuged at 2,000 g for $2 \mathrm{~min}$ at $4{ }^{\circ} \mathrm{C}$, to save the supernatant as the nucleolar fraction $^{34}$.

\section{Immunoprecipitation}

Recombinant protein G-agarose beads $(10 \mu \mathrm{l}$ per sample; Invitrogen, Carlsbab, CA, USA) were equilibrated by gently agitation in lysis buffer $(50 \mathrm{mM}$ Tris- $\mathrm{HCl} \mathrm{pH} 8$, $150 \mathrm{mM} \mathrm{NaCl}, 1 \%$ Triton X-100, $2 \mathrm{mM} \mathrm{Na} \mathrm{VO}_{4}, 25 \mathrm{mM}$
$\mathrm{NaF}, 10 \mathrm{mM} \mathrm{Na} \mathrm{MoO}_{4}, 1 \mathrm{mM}$ PMSF, and $1 \times$ complete protease inhibitor mixture). We quantified $500 \mathrm{ug}$ of protein and the lysates were pre-cleared with equilibrated beads for $2 \mathrm{~h}$ at $4{ }^{\circ} \mathrm{C}$, the beads were removed by centrifugation at $3,500 \mathrm{rpm}$ for $5 \mathrm{~min}$ and the pre-cleared extracts incubated overnight at $4{ }^{\circ} \mathrm{C}$ with the appropriate antibody. Incubations with an irrelevant IgG antibody were carried out in parallel. Thereafter, equilibrated protein G-agarose beads blocked previously with $4 \%$ BSA were added to the lysates and incubated overnight at $4{ }^{\circ} \mathrm{C}$. Immune complexes were collected by centrifugation at $3,500 \mathrm{rpm}$ for $5 \mathrm{~min}$, washed twice for $10 \mathrm{~min}$ with $500 \mu \mathrm{l}$ of washing buffer $(50 \mathrm{mM}$ Tris- $\mathrm{HCl}, 150 \mathrm{mM} \mathrm{NaCl}, 5 \mathrm{mM}$ EDTA, 1\% Tritón X-100, 1X complete protease inhibitor, $1 \mathrm{mM}$ PMSF). Bound proteins were eluted from beads by boiling in sample buffer $(50 \mathrm{mM}$ Tris- $\mathrm{HCl} \mathrm{pH} 6.8,2 \%$ $(\mathrm{w} / \mathrm{v})$ SDS, $10 \%$ (v/v) glycerol, $0.1 \%(\mathrm{v} / \mathrm{v})$ 2-mercaptoethanol, $0.001 \%$ bromophenol blue), prior to being subjected to western blot analysis. $\mathrm{C} 2 \mathrm{C} 12$ cell lysates expressing GFP-tagged proteins were subjected to IP using the GFP-Trap ${ }^{\circledR}$ system (Chromotek, Germany), according to the manufacturer's instructions.

\section{Quantitative reverse PCR (RT-qPCR)}

For analysis of rRNA transcripts, total RNA was extracted using Direct-zol ${ }^{\text {TM }}$ RNA Miniprep Kit (Zymo Research, Irvine, CA, USA), according to the manufacturer's instructions. And further analyzed by qRT-PCR with specific primers amplifying $45 \mathrm{~S}$ pre-rRNA (forward, 5'-GTGTCCAAGTGTTCATGCCA; reverse, 5'CGATCTAAGAGTGAGCAACGAC), $18 \mathrm{~S}$ rRNA (forward, 5'-TTCCGACCATAAACGATGCC; reverse, 5'GCTCCACCAACTAAGAACGG), $28 \mathrm{~S}$ rRNA (forward, 5'-GATGGTGAACTATGCTTGGG; reverse, 5'-GAATAGGTTGAGATCGTTTCGG), and GAPDH mRNA (forward, 5'-CTTGGGCTACACTGAGGACC; reverse, 5'-CTGTTGCTGTAGCCGTATTC). For analysis of $D A G 1$ mRNA expression, the following primers were used: forward, 5'-GAGATCATCAAGGTGTCTGCA and reverse, 5'-GTGGCTCATTGTGGTCTTCAG. RTqPCR reactions were carried out in the StepOneplus System (Life technologies), using KAPA SYBR ${ }^{\circledR}$ FAST One-Step qRT-PCR Master Mix $(2 \times)$ Kit, and further analyzed with the StepOne Software v2.3. The data were analyzed by comparative method $2^{-\Delta \Delta C T}$.

\section{RNA pol I reporter assays}

C2C12 cells stably expressing GFP-ICD- $\beta$ DG or GFP alone were co-transfected with both the Renilla Luciferase vector (transcribed by RNA polymerase II) as a control to normalize for differences in transfection efficiency and with the firefly luciferase RNA polymerase I reporter vector (pMrTsp-9-T10). The two vectors were kindly donated by Gernot Längst Lab., Regensburg University, 
Germany. After $48 \mathrm{~h}$, the luciferase activity was measured using Dual Luciferase Assay kit (Promega). The firefly luciferase counts of the RNA polymerase I reporter were divided by the Renilla luciferase counts and compared to GFP control transfections.

\section{Cell proliferation assays}

C2C12 cells stably expressing GFP-ICD- $\beta$ DG or GFP alone were harvested and plated in triplicate onto 12 wells microplates at $1 \times 10^{3}$ cells $/ \mathrm{mL}$ confluence. Proliferation was measured for 13 days using the MTT (3-(4,5-dimethylthiazole) - 2-5-diphenyl tetrazolium bromide) commercial kit (Sigma-Aldrich), following the manufacturer's instructions.

\section{Chromatin immunoprecipitation assays}

C2C12 cells were incubated with $1 \%$ formaldehyde in PBS for $10 \mathrm{~min}$ at room temperature. Cross-link reaction was stopped by adding glycine to a final concentration of $125 \mathrm{mM}$. Cells were washed and harvested with cold PBS. After centrifugation at $1500 \mathrm{~g}$, the pellet was resuspended in sonication buffer $(50 \mathrm{mM}$ Hepes $\mathrm{pH} 7.9$, $140 \mathrm{mM} \mathrm{NaCl}, 1 \mathrm{mM}$ EDTA, $1 \%$ Triton X-100, 0.1\% sodium deoxycholate, $0.1 \%$ SDS and protease inhibitors). Soluble and sheared chromatin were obtained by applying five cycles of sonication on ice at $10 \%$ of amplitude for $20 \mathrm{~s}$ (Q55 sonicator, Qsonica) and recovered by centrifugation. Soluble chromatin was preclarified by mixing with $50 \mu$ l of recombinant protein G-agarose beads (rPGA Invitrogen) and incubated with shaking for $1 \mathrm{~h}$ at $4{ }^{\circ} \mathrm{C}$. The mix was centrifuged at $3,000 \times \mathrm{g}$ for $1 \mathrm{~min}$ to remove rPGA. Twenty five micrograms of pre-clarified chromatin diluted 1:10 in sonication buffer were mixed with $7.8 \mu \mathrm{g}$ of mouse purified serum anti- $\beta$-dystroglycan or $7.8 \mu \mathrm{g}$ of mouse IgG (irrelevant control). Finally $25 \mu \mathrm{l}$ of rPGA were added to each sample and incubate with shaking overnight at $4{ }^{\circ} \mathrm{C}$. Immunoprecipitated DNA-protein complexes were extensively and sequentially washed with sonication buffer, wash buffer A (50 mM Hepes $\mathrm{pH} 7.9$, $500 \mathrm{mM} \mathrm{NaCl}, 1 \mathrm{mM}$ EDTA, $1 \%$ Triton X-100, $0.1 \%$ sodium deoxycholate, $0.1 \%$ SDS), wash buffer B $(20 \mathrm{mM}$ Tris-Cl pH 8, 1 mM EDTA, $250 \mathrm{mM} \mathrm{LiCl,} \mathrm{0.5 \%} \mathrm{NP40,}$ $0.5 \%$ deoxycholate), and TE buffer. Finally, the pellet was incubated with shaking for $10 \mathrm{~min}$ at $65^{\circ} \mathrm{C}$ in elution buffer $(50 \mathrm{mM}$ Tris-Cl pH 8, $1 \mathrm{mM}$ EDTA, 1\% SDS, 50 $\mathrm{mM} \mathrm{NaHCO}_{3}$ ). Supernatant was recovered by centrifugation and the cross-link reversion was carried out by adding RNAase $\mathrm{A}$ and Proteinase $\mathrm{K}$ to each sample and incubating with shaking for $4 \mathrm{~h}$ at $65^{\circ} \mathrm{C}$. DNA was recovered by phenol-chloroform extraction and ethanol precipitation. Twenty nanograms of DNA was used to perform quantitative PCR (qPCR), using SYBR green and rDNA-specific primers as previously reported ${ }^{35,36}$.

\section{Ribosomal profile analysis}

Cells grown at $80-90 \%$ confluency were harvested, washed with PBS with $100 \mu \mathrm{g} / \mathrm{mL}$ cycloheximide and centrifuged at $5,000 \mathrm{rpm}$ for $5 \mathrm{~min}$ at $4{ }^{\circ} \mathrm{C}$, prior to suspension in $200 \mu \mathrm{l}$ of lysis buffer containing $100 \mu \mathrm{g} / \mathrm{mL}$ cycloheximide and $1 \times$ complete protease inhibitor mixture. Thereafter cells were centrifuged for $10 \mathrm{~min}$ at $10,000 \mathrm{rpm}$ and the supernatant was layered on top of a $15-50 \%$ sucrose gradient to be centrifuged at $25,000 \mathrm{rpm}$ for $5: 30 \mathrm{~h}$ at $4{ }^{\circ} \mathrm{C}$ in a Beckman SW28Ti rotor. All gradients were scanned at $260 \mathrm{~nm}$ from the top with an ISCO gradient collector. Collected fractions were precipitated with ethanol and centrifuged at $15,000 \mathrm{rpm}$ for $30 \mathrm{~min}$ to obtain ribosomal particles.

\section{Acknowledgments}

This work was funded by CONACYT Mexico, a grant to BC (237123) and MRC PhD studentship to LAJ (G1000405-1/1 MR//J500513/1.

\section{Author details \\ 'Departamento de Genética y Biología Molecular, Centro de Investigación y de Estudios Avanzados Del Instituto Politécnico Nacional, 07360 Ciudad de México, Mexico. ${ }^{2}$ Departamento de Neurociencia Cognitiva, Instituto de Fisiología Celular, Universidad Nacional Autónoma de México, 04510 Ciudad de México, Mexico. ${ }^{3}$ Laboratorio de Hematobiología, Escuela Nacional de Medicina y Homeopatía, Instituto Politécnico Nacional, 07320 Ciudad de México, Mexico. ${ }^{4}$ Laboratorio de Medicina Genómica, Instituto Nacional de Rehabilitación, 14389 Ciudad de México, Mexico. ${ }^{5}$ Biochemistry Centre Regensburg (BCR), Universität Regensburg, 93053 Regensburg, Germany. ${ }^{6}$ Department of Biomedical Science, University of Sheffield, Sheffield S10 2TN, UK. ${ }^{7}$ Departamento de Toxicología, Centro de Investigación y de Estudios Avanzados Del Instituto Politécnico Nacional, 07000 Ciudad de México, Mexico. ${ }^{8}$ Department of Medicine, Lillehei Heart Institute, University of Minnesota, Minneapolis, MN, USA}

Conflict of interest

The authors declare that they have no conflict of interest.

\section{Publisher's note}

Springer Nature remains neutral with regard to jurisdictional claims in published maps and institutional affiliations.

Supplementary Information accompanies this paper at (https://doi.org/ 10.1038/s41419-019-1454-z).

Received: 26 September 2018 Revised: 21 January 2019 Accepted: 11 February 2019

Published online: 27 February 2019

\section{References}

1. Vieceli Dalla Sega, F. et al. Context-dependent function of ROS in the vascular endothelium: The role of the Notch pathway and shear stress. Biofactors 43, 475-485 (2017).

2. Walter, J., Kemmerling, N., Wunderlich, P. \& Glebov, K. Y-Secretase in microglia implications for neurodegeneration and neuroinflammation. J. Neurochem. 143, 445-454 (2017).

3. Leocadio, D., Mitchell, A. \& Winder, S. J. Y-Secretase dependent nuclear targeting of dystroglycan. J. Cell. Biochem. 117, 2436 (2016).

4. Leiton, C. V. et al. Laminin promotes metalloproteinase-mediated dystroglycan processing to regulate oligodendrocyte progenitor cell proliferation. J. Neurochem. 135, 522-538 (2015).

5. Moore, C. J. \& Winder, S. J. Dystroglycan versatility in cell adhesion: a tale of multiple motifs. Cell. Commun. Signal. 8, 3 (2010). 
6. Moore, C. J. \& Winder, S. J. The inside and out of dystroglycan posttranslational modification. Neuromuscul. Disord. 22, 959-965 (2012).

7. Bozzi, M., Morlacchi, S., Bigotti, M. G., Sciandra, F. \& Brancaccio, A. Functional diversity of dystroglycan. Matrix Biol. 28, 179-187 (2009).

8. Vásquez-Limeta, A. et al. Nuclear import of $\beta$-dystroglycan is facilitated by ezrin-mediated cytoskeleton reorganization. PLoS ONE 9, e90629 (2014).

9. Lara-Chacón, B. et al. Characterization of an importin alpha/beta-recognized nuclear localization signal in beta-dystroglycan. J. Cell. Biochem. 110, 706-717 (2010).

10. Gracida-Jiménez, V. et al. Retrograde trafficking of $\beta$-dystroglycan from the plasma membrane to the nucleus. Sci. Rep. 7, 9906 (2017).

11. Martínez-Vieyra, I. A. et al. A role for $\beta$-dystroglycan in the organization and structure of the nucleus in myoblasts. Biochim. Biophys. Acta 1833, 698-711 (2013).

12. Vélez-Aguilera, G. et al. Control of nuclear $\beta$-dystroglycan content is crucial for the maintenance of nuclear envelope integrity and function. Biochim. Biophys. Acta 1865, 406-420 (2018)

13. Mathew, G. et al. Nuclear targeting of dystroglycan promotes the expression of androgen regulated transcription factors in prostate cancer. Sci. Rep. 3, 2792 (2013).

14. Sbardella, D. et al. Enzymatic processing by MMP-2 and MMP-9 of wild-type and mutated mouse $\beta$-dystroglycan. IUBMB Life 64, 988-994 (2012).

15. Sbardella, D. et al. a-dystroglycan is a potential target of matrix metalloproteinase MMP-2. Matrix Biol. 41, 2-7 (2015).

16. Mitchell, A. et al. Dystroglycan function is a novel determinant of tumor growth and behavior in prostate cancer. Prostate 73, 398-408 (2013).

17. Sleeman, J. E. \& Trinkle-Mulcahy, L. Nuclear bodies: new insights into assembly/dynamics and disease relevance. Curr. Opin. Cell Biol. 28, 76-83 (2014).

18. Sharifi, S. \& Bierhoff, H. Regulation of RNA polymerase I transcription in development, disease, and aging. Annu. Rev. Biochem. https://doi.org/10.1146/ annurev-biochem-062917-012612 (2018).

19. Riemersma, M. et al. Absence of $a-$ and $\beta$-dystroglycan is associated with Walker-Warburg syndrome. Neurology 84, 2177-2182 (2015).

20. Tsekrekou, M., Stratigi, K. \& Chatzinikolaou, G. The Nucleolus: In Genome Maintenance and Repair. Int. J. Mol. Sci. 18, https://doi.org/10.3390/ ijms18071411 (2017).

21. Shav-Tal, Y. et al. Dynamic sorting of nuclear components into distinct nucleolar caps during transcriptional inhibition. Mol. Biol. Cell. 16, 2395-2413 (2005).
22. Lipscomb, L., Piggott, R. W., Emmerson, T. \& Winder, S. J. Dasatinib as a treatment for Duchenne muscular dystrophy. Hum. Mol. Genet. 25, 266-274 (2016).

23. Bozzi, M. et al. Enzymatic processing of beta-dystroglycan recombinant ectodomain by MMP-9: identification of the main cleavage site. IUBMB Life 61, 1143-1152 (2009).

24. Martin, C. et al. Lamin B1 maintains the functional plasticity of nucleoli. J. Cell. Sci. 122, 1551-1562 (2009).

25. Legartová, S. et al. Nuclear structures surrounding internal lamin invaginations. J. Cell. Biochem. 115, 476-487 (2014).

26. Sen Gupta, A. \& Sengupta, K. Lamin B2 modulates nucleolar morphology, dynamics, and function. Mol. Cell. Biol. 37, https://doi.org/10.1128/MCB.0027417 (2017).

27. Christie, M. et al. Structural biology and regulation of protein import into the nucleus. J. Mol. Biol. 428, 2060-2090 (2016).

28. Lindström, M. S. NPM1/B23: a multifunctional chaperone in ribosome biogenesis and chromatin remodeling. Biochem. Res. Int. 2011, 195209 (2011)

29. Panov, K. I., Friedrich, J. K., Russell, J. \& Zomerdijk, J. C. UBF activates RNA polymerase I transcription by stimulating promoter escape. EMBO J. 25, 3310-3322 (2006)

30. Aubert, M., O'Donohue, M. F., Lebaron, S. \& Gleizes, P. E. Pre-ribosomal RNA processing in human cells: from mechanisms to congenital diseases. Biomolecules 8, https://doi.org/10.3390/biom8040123 (2018).

31. Yang Kai, Y. J. \& Jing, Ji Nucleolar Stress: hallmarks, sensing mechanism and diseases. Cell Stress 2, 125-140 (2018).

32. Németh, A. \& Grummt, I. Dynamic regulation of nucleolar architecture. Curr. Opin. Cell Biol. 52, 105-111 (2018).

33. Pereboev, A. V., Ahmed, N., thi Man, N. \& Morris, G. E. Epitopes in the interacting regions of beta-dystroglycan (PPXY motif) and dystrophin (WW domain). Biochim. Biophys. Acta 1527, 54-60 (2001).

34. Hernández-Ibarra, J. A., Laredo-Cisneros, M. S., Mondragón-González, R., Santamaría-Guayasamín, N. \& Cisneros, B. Localization of a-dystrobrevin in cajal bodies and nucleoli: a new role for a-dystrobrevin in the structure/stability of the nucleolus. J. Cell. Biochem. 116, 2755-2765 (2015).

35. Todd, M. A., Huh, M. S. \& Picketts, D. J. The sub-nucleolar localization of PHF6 defines its role in rDNA transcription and early processing events. Eur. J. Hum. Genet. 24, 1453-1459 (2016).

36. Hisaoka, M., Ueshima, S., Murano, K., Nagata, K. \& Okuwaki, M. Regulation of nucleolar chromatin by B23/nucleophosmin jointly depends upon its RNA binding activity and transcription factor UBF. Mol. Cell. Biol. 30, 4952-4964 (2010). 